\title{
A PI-Type Sliding Mode Controller Design for PMSG-Based Wind Turbine
}

\author{
Jun Liu, Feihang Zhou $\mathbb{D}^{D}$, Chencong Zhao $\mathbb{D}$, and Zhuoran Wang \\ College of Automation, Xian University of Technology, China \\ Correspondence should be addressed to Feihang Zhou; qq987102679@126.com
}

Received 2 April 2019; Revised 10 May 2019; Accepted 28 May 2019; Published 19 June 2019

Guest Editor: Baltazar Aguirre-Hernandez

Copyright (C) 2019 Jun Liu et al. This is an open access article distributed under the Creative Commons Attribution License, which permits unrestricted use, distribution, and reproduction in any medium, provided the original work is properly cited.

\begin{abstract}
Because the PMSG (permanent magnet synchronous generator)-based WECS (wind energy conversion system) has some uncertainties, the conventional control strategy with poor robustness is sometimes difficult to meet the performance requirements of control. In order to ensure efficient and stability of the system, this paper proposed a novel PI (proportional-integral)-type SMC (sliding mode control) strategy for PMSG-based WECS uncertainties and presented the detailed analysis and design process. Compared with the conventional control method, the PI-type SMC proposed in this paper not only can make the closed-loop system globally stable, but also has a better robustness and slightly reduced the current ripple and distortion. Finally, the simulation results verify the correctness and effectiveness of this algorithm.
\end{abstract}

\section{Introduction}

Environment problems such air pollution and global warming caused by fossil fuels have drawn the world's attention to exploration and utilization of renewable energy sources, in recent years [1-5]. At present, wind energy is the fastest growing renewable energy source and is most prevalent in coastal regions spanning temperate and boreal climates [6-8]. There is great potential for wind power development in China, USA, Denmark, and other countries, due to their high average wind velocities [9]. Therefore, the research on wind power generation technology has a significant value nowadays. Compared with the constant-speed constant-frequency wind turbine, the variable-speed constant-frequency wind turbines can obtain the maximum energy conversion due to its rotational speed could vary with wind speed to ensure that the system has the OTSR (optimal tip speed ratio) and maximum wind energy utilization coefficient. The variable-speed constantfrequency wind energy conversion system (WECS) consists of DFIG (doubly fed induction generator)-based WECS and PMSG (permanent magnet synchronous generator)-based WECS. The PMSG-based WECS was selected to study in this paper, due to the fact that PMSG has many superior characteristics such as wider speed control range, higher reliability, and more efficient performance compared with DIFG [10]

In fact, the practical systems have many uncertainties. The uncertainties of PMSG or PMSM (permanent magnet synchronous motor) consist of the unmodeled converter dynamics and the parameters perturbations [11-14]. A robust control scheme for PMSM uncertainties based on an adaptive DOB (disturbance observer) was introduced in [11]. The results indicated that the controller obtained a good control performance. Reference [12] proposed a robust nonlinear predictive control strategy for PMSM uncertainties. The control system obtained a high speed tracking precision. In [13], a PFC (predictive functional control) + ESO (extended state observer) method was studied. After that, the effectiveness of this new method was verified. Reference [14] proposed a novel decoupled PI current control method for the PMSGbased WECS. This method can successfully achieve improved the transient performances and the nominal performance recovery under the model uncertainty.

SMC (sliding mode control) first proposed in the early 1950s has a good robustness and powerful ability to reject the plant uncertainties and disturbances $[15,16]$. References $[15$, 16] summarized the development of SMC and examined key technical research issues and future perspectives. Although 


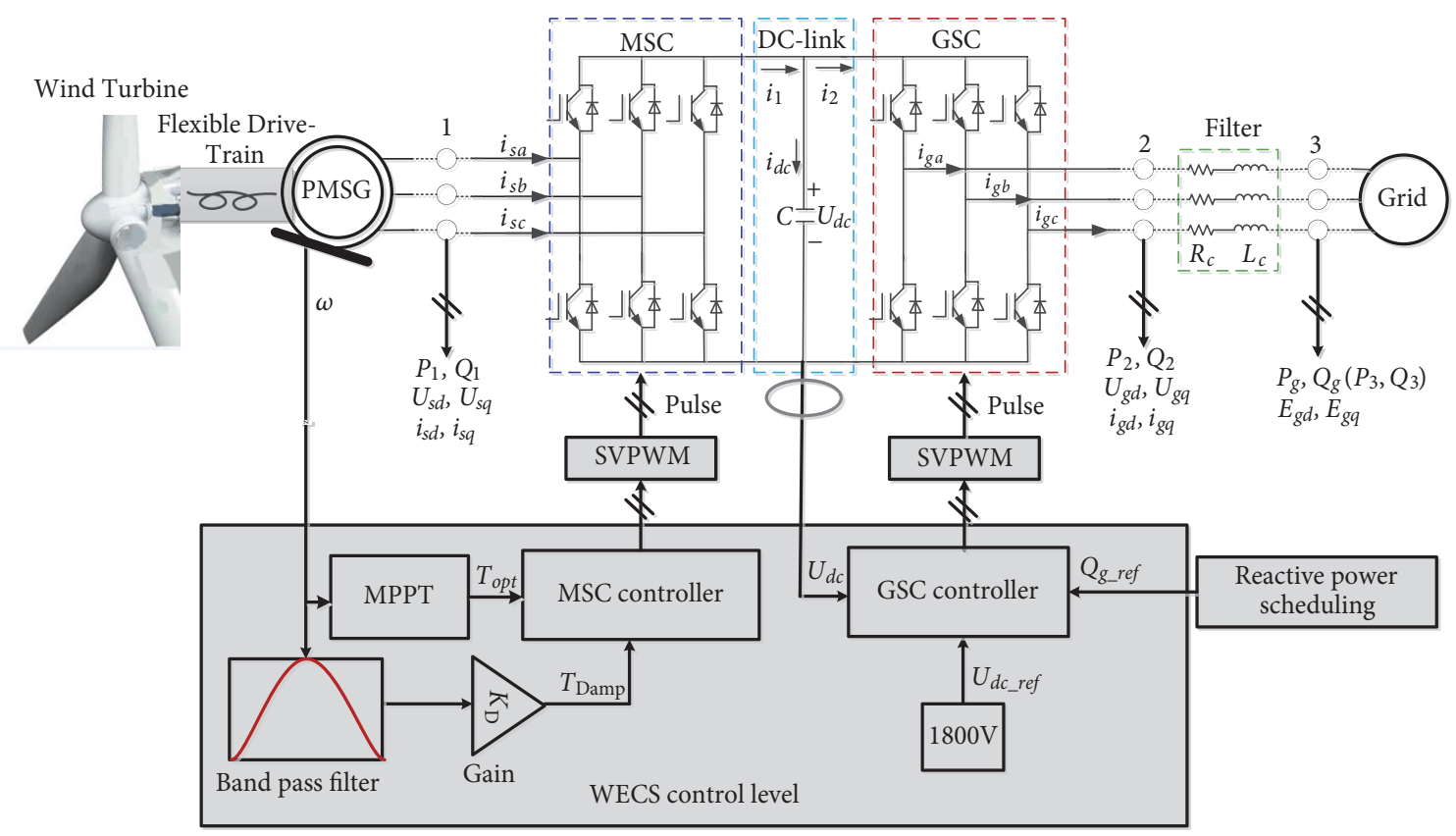

FIgURE 1: A WECS configuration.

the SMC has been widely and extensively employed in some industrial applications for a long term, it is still the researching focus for scholars and worth studying in depth. A DPC (direct power control) based on SMC for the gridconnected WECS was presented in [17]. When the grid voltage is unbalanced, the controller also can regulate the instantaneous active and reactive powers directly in stator stationary reference frame. Reference [18] enhanced the exponential reaching law to improve the control efficiency and performance of SMC used in PMSG-based WECS.

An adaptive second-order SMC strategy was explored in [19]. This method can effectively deals with the presence of model uncertainties, intrinsic nonlinear behavior of WECS, and random wind. A SMC method for mismatched uncertainties via a nonlinear DOB was developed in [20]. Meanwhile, the I-SMC (integral sliding-model control) with a good steady-state precision was mentioned in $[20,21]$. The PI-type SMC is derived by the I-SMC and FBL (feedback linearization) approach and has been widely used in renewable energy conversion systems and the electric motor drives [21-23]. Furthermore, compared with the I-SMC, the proportional and integral parameters of the PI-type SMC are able to be adjusted to better meet the control performance indexes such as the celerity and accuracy.

Based on the above background, this paper presents a novel PI-type SMC for the PMSG-based WECS. Although the inspiration for this paper comes from literature [2023], the whole designing thought and procedure of the proposed controller are completely different from the methods in [20-23]. Furthermore, [20,23] just only referred to the control of PMSG without the consideration of gridconnected control. And the study subjects in $[22,23]$ and this paper are different. At the same time, the suppression of flexible drive-train torsional vibration also has been regarded as a control target in this paper. Then, we set up a detailed $2 \mathrm{MW}$ WECS simulation test platform based on MATLAB/SIMULINK/SimPowerSysterms to verify the effectiveness and correctness of the proposed method. A large number of existing packaging modules in SimPowerSysterms are used in the simulation test platform that is relatively close to the real physical system. Finally, the simulation results indicate the proposed strategy has good control performance.

\section{PMSG-Based WECS Model}

The simplified PMSG-based WECS mainly consists of a wind turbine, a flexible drive-train, a PMSG, fully rated converters, and its control level shown in Figure 1. In order to capture the maximum wind energy, the maximum power point tracking (MPPT) strategy is adopted to control the machine-side converter (MSC). In the loop control level, the grid-side converter (GSC) control is to regulate the reactive power and keep DC-link voltage $U_{d c}$ stable at $1800 \mathrm{~V}$. Meanwhile, in order to suppress the torsional vibration of flexible drive-train, the damping compensation torque $T_{\text {Damp }}$ was introduced.

2.1. PMSG and MSC Dynamic Model. The PMSG and MSC mathematical model is $[5,20-27]$

$$
\begin{aligned}
\frac{\mathrm{d} i_{s d}}{\mathrm{~d} t}= & -\frac{R_{s}}{L_{s d}} i_{s d}+\frac{L_{s q}}{L_{s d}} n_{p} \omega i_{s q}+\frac{1}{L_{s d}} U_{s d}-\frac{1}{L_{s d}} \varepsilon_{s d} \\
\frac{\mathrm{d} i_{s q}}{\mathrm{~d} t}= & -\frac{R_{s}}{L_{s q}} i_{s q}-\frac{L_{s d}}{L_{s q}} n_{p} \omega i_{s d}-\frac{n_{p} \omega \psi}{L_{s q}}+\frac{1}{L_{s q}} U_{s q} \\
& -\frac{1}{L_{s q}} \varepsilon_{s q}
\end{aligned}
$$


where $U_{s d}$ and $U_{s q}$ are the d-axis and q-axis stator armature voltages. $i_{s d}$ and $i_{s q}$ are the $\mathrm{d}$-axis and q-axis components of stator currents. $L_{s d}$ and $L_{s q}$ are the d-axis and q-axis stator inductances. $\omega$ is the rotor speed. $n_{\mathrm{p}}$ represents magnetic pole logarithms. $R_{\mathrm{s}}$ is the stator resistance. $\psi$ represents the permanent magnet chain. And the disturbance vector $\varepsilon_{s d}$ and $\varepsilon_{s q}$ represent model uncertainties including the external disturbances and the PWM offset. $\varepsilon_{s d}$ and $\varepsilon_{s q}$ were generally assumed to be bounded by $D_{s d}$ and $D_{s d}$.

$$
\begin{aligned}
& \left|\varepsilon_{s d}\right| \leq D_{s d} \\
& \left|\varepsilon_{s d}\right| \leq D_{s q}
\end{aligned}
$$

where $D_{s d}$ and $D_{s q}$ are the boundaries of $\varepsilon_{s d}$ and $\varepsilon_{s q}$.

The PMSG torque is given by

$$
T_{g}=1.5 n_{p}\left[\left(L_{s d}-L_{s q}\right) i_{s d} i_{s q}+\psi i_{s q}\right]
$$

2.2. GSC Dynamic Model. The GSC dynamic model is given by

$$
\begin{aligned}
& \frac{\mathrm{d} i_{g d}}{\mathrm{~d} t}=-\frac{R_{c}}{L_{c}} i_{g d}+\omega_{g} i_{g q}+\frac{1}{L_{c}} E_{g d}-\frac{1}{L_{c}} U_{g d}-\frac{1}{L_{c}} \varepsilon_{g d} \\
& \frac{\mathrm{d} i_{g q}}{\mathrm{~d} t}=-\frac{R_{c}}{L_{c}} i_{g q}-\omega_{g} i_{g d}+\frac{1}{L_{c}} E_{g q}-\frac{1}{L_{c}} U_{g q}-\frac{1}{L_{c}} \varepsilon_{g q}
\end{aligned}
$$

where $U_{g d}$ and $U_{g q}$ are the control voltages. $i_{g d}$ and $i_{g q}$ are the components of grid-side currents. $\omega_{g}$ is the power grid frequency. $L_{c}$ and $R_{c}$ are the filter inductance and resistance. $E_{q d}$ and $E_{g q}$ express the d-axis and q-axis power grid potential components (usually, $E_{g q}=0$ ). The $\omega_{g}$ and $E_{g d}$ can be gotten by the voltage phase-locked loop. $\varepsilon_{g d}$ and $\varepsilon_{g q}$ are also the uncertainties and meet

$$
\begin{aligned}
& \left|\varepsilon_{g d}\right| \leq D_{g d} ; \\
& \left|\varepsilon_{g d}\right| \leq D_{g q}
\end{aligned}
$$

$D_{g d}$ and $D_{g q}$ are the boundaries of $\varepsilon_{g d}$ and $\varepsilon_{g q}$.

\section{PI-Type Sliding Mode Controller Design}

3.1. Control Objectives. If the state vector $\boldsymbol{x}$ and the reference state vector $\boldsymbol{x}_{-}$ref are

$$
\begin{aligned}
\boldsymbol{x} & =\left[\begin{array}{llll}
i_{s d} & i_{s q} & i_{g d} & i_{g q}
\end{array}\right]^{\mathrm{T}} \\
\boldsymbol{x}_{\text {ref }} & =\left[\begin{array}{llll}
i_{\text {sd_ref }} & i_{\text {sq } \text { ref }} & i_{\text {gd_sef }} & i_{\text {gq sef }}
\end{array}\right]^{\mathrm{T}}
\end{aligned}
$$

the control objectives of WECS can be expressed as

$$
\lim _{t \longrightarrow+\infty} \boldsymbol{e}=\lim _{t \longrightarrow+\infty} \boldsymbol{x}_{r e f}-\boldsymbol{x}=\mathbf{0}
$$

where $\boldsymbol{e}$ is the error vector. In the above formula, usually we have

$$
\begin{aligned}
& i_{\text {sd_ref }}=0 \\
& i_{\text {sq_ref }}=\frac{2 T_{\text {g_ref }}}{3 n_{p} \psi}=\frac{2\left(T_{o p t}+T_{\text {Damp }}\right)}{3 n_{p} \psi} \\
& i_{\text {gd_ref }}=\left(K_{P}+\frac{K_{I}}{s}\right)\left(U_{d c_{\_} r e f}-U_{d c}\right) \\
& i_{\text {gq_ref }}=\frac{Q_{\text {g_ref }}}{E_{g d}}
\end{aligned}
$$

where $K_{P}$ and $K_{I}$ are the PI (proportional-integral) parameters. The optimal torque $T_{\text {opt }}$ in (9) meets $[1,26-29]$

$$
T_{o p t}=K_{o p t} \omega^{2} \quad \text { with } K_{o p t}=\frac{\pi \rho R^{5} C_{P \_ \text {max }}}{2 \lambda_{o p t}^{3}}
$$

where $R$ is the wind wheel radius, $\rho$ is the air density, $C_{P_{-} \max }$ is defined as the maximum wind energy conversion coefficient, $\lambda_{\text {opt }}$ is the OTSR (optimal tip speed ratio), and the damping compensation torque $T_{\text {Damp }}$ is given by [29-38]

$$
T_{\text {Damp }}=K_{D} H(s) \omega
$$

where $K_{D} \in R^{+}$and $H(s)$ is the transfer function of bandpass filter shown in [29-38].

3.2. Design of Proportional-Integral (PI)-Type Sliding Mode Controller. The PI-type sliding surface $\boldsymbol{S}$ can be defined as

$$
S=\left(K+\frac{1}{S} \boldsymbol{I}\right) \boldsymbol{e}
$$

where

$$
\begin{aligned}
& \boldsymbol{S}=\left[\begin{array}{llll}
S_{1} & S_{2} & S_{3} & S_{4}
\end{array}\right]^{\mathrm{T}} \\
& \boldsymbol{K}=\operatorname{diag}\left\langle K_{1}, K_{2}, K_{3}, K_{4}\right\rangle \\
& \boldsymbol{I}=\operatorname{diag}\left\langle I_{1}, I_{2}, I_{3}, I_{4}\right\rangle
\end{aligned}
$$

$s$ is Laplace variable. $K_{i} \in R^{+}$and $I_{i} \in R^{+}(i=1,2,3,4)$. Obviously, we also can get

$$
\begin{aligned}
& S_{1} \varepsilon_{s d} \leq\left|S_{1} \varepsilon_{s d}\right|=D_{s d} S_{1} \operatorname{sgn}\left(S_{1}\right) \\
& S_{2} \varepsilon_{s q} \leq\left|S_{2} \varepsilon_{s q}\right|=D_{s q} S_{2} \operatorname{sgn}\left(S_{2}\right) \\
& S_{4} \varepsilon_{g d} \leq\left|S_{4} \varepsilon_{g d}\right|=D_{g d} S_{4} \operatorname{sgn}\left(S_{4}\right) \\
& S_{5} \varepsilon_{g q} \leq\left|S_{5} \varepsilon_{g q}\right|=D_{g q} S_{5} \operatorname{sgn}\left(S_{5}\right)
\end{aligned}
$$

if the Lyapunov function is defined as

$$
V=\frac{1}{2} \boldsymbol{S}^{\mathrm{T}} \boldsymbol{S}=\sum_{i=1}^{4} V_{i}
$$


where

$$
V_{i}=\frac{1}{2} S_{i}^{2}
$$

Equations (19)-(22) can be gotten by taking the derivative of (17).

$$
\begin{aligned}
& \dot{V}_{1}=S_{1} \dot{S}_{1}=S_{1}\left(K_{1} \dot{e}_{s d}+I_{1} e_{s d}\right) \\
& =S_{1}\left\{K_{1}\left(\begin{array}{c}
\dot{i}_{s d \_r e f}+\frac{R_{s}}{L_{s d}} i_{s d}-\frac{L_{s q}}{L_{s d}} n_{p} \omega i_{s q} \\
-\frac{1}{L_{s d}} U_{s d}+\frac{1}{L_{s d}} \varepsilon_{s d}
\end{array}\right)\right. \\
& \left.+I_{1} e_{s d}\right\} \\
& \leq S_{1}\left\{K_{1}\left(\begin{array}{c}
i_{s d s e f}+\frac{R_{s}}{L_{s d}} i_{s d}-\frac{L_{s q}}{L_{s d}} n_{p} \omega i_{s q} \\
-\frac{1}{L_{s d}} U_{s d}+\frac{1}{L_{s d}} D_{s d} \operatorname{sgn}\left(S_{1}\right)
\end{array}\right)\right. \\
& \left.+I_{1} e_{s d}\right\} \\
& \dot{V}_{2}=S_{2} \dot{S}_{2}=S_{2}\left(K_{2} \dot{e}_{s q}+I_{2} e_{s q}\right)
\end{aligned}
$$

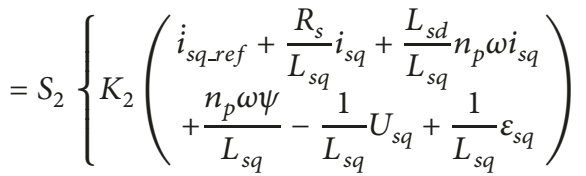

$$
\begin{aligned}
& \left.+I_{2} e_{s q}\right\}
\end{aligned}
$$

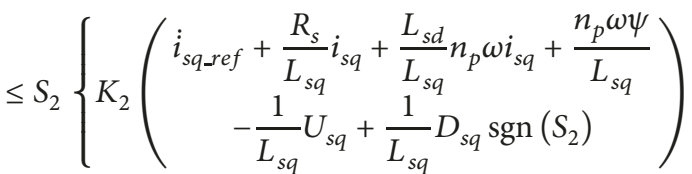

$$
\begin{aligned}
& \left.+I_{2} e_{s q}\right\}
\end{aligned}
$$

(19)$$
\dot{V}_{3}=S_{3} \dot{S}_{3}=S_{3}\left(K_{3} \dot{e}_{g d}+I_{3} e_{g d}\right)
$$

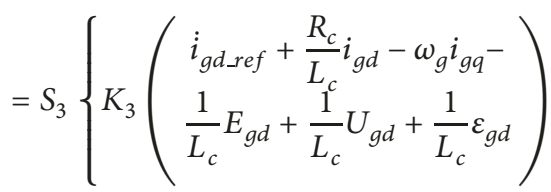$$
\left.+I_{3} e_{g d}\right\}
$$$$
\leq S_{3}\left\{K_{3}\left(\begin{array}{c}
i_{g d s e f}+\frac{R_{c}}{L_{c}} i_{g d}-\omega_{g} i_{g q^{-}} \\
\frac{1}{L_{c}} E_{g d}+\frac{1}{L_{c}} U_{g d}+\frac{1}{L_{c}} D_{g d} \operatorname{sgn}\left(S_{4}\right)
\end{array}\right)\right.
$$$$
\left.+I_{3} e_{g d}\right\}
$$$$
\dot{V}_{4}=S_{4} \dot{S}_{4}=S_{4}\left(K_{4} \dot{e}_{g q}+I_{4} e_{g q}\right)
$$$$
=S_{4}\left\{K_{4}\left(\begin{array}{c}
i_{g q \text { ref }}+\frac{R_{c}}{L_{c}} i_{g q}+\omega_{g} i_{g d^{-}} \\
\frac{1}{L_{c}} E_{g q}+\frac{1}{L_{c}} U_{g q}+\frac{1}{L_{c}} \varepsilon_{g q}
\end{array}\right)\right.
$$$$
\left.+I_{4} e_{g q}\right\}
$$$$
\leq S_{4}\left\{K_{4}\left(\begin{array}{c}
i_{g q r e f}+\frac{R_{c}}{L_{c}} i_{g q}+\omega_{g} i_{g d}-\frac{1}{L_{c}} E_{g q} \\
+\frac{1}{L_{c}} U_{g q}+\frac{1}{L_{c}} D_{g q} \operatorname{sgn}\left(S_{3}\right)
\end{array}\right)\right.
$$$$
\left.+I_{4} e_{g q}\right\}
$$

Let

$$
\begin{gathered}
K_{1}\left(\dot{i}_{s d_{-} r e f}+\frac{R_{s}}{L_{s d}} i_{s d}-\frac{L_{s q}}{L_{s d}} n_{p} \omega i_{s q}-\frac{1}{L_{s d}} U_{s d}\right. \\
\left.+\frac{1}{L_{s d}} D_{s d} \operatorname{sgn}\left(S_{1}\right)\right)+I_{1} e_{s d}=-\gamma_{1} S_{1}
\end{gathered}
$$




$$
\begin{aligned}
& K_{2}\left(\dot{i}_{s q r e f}+\frac{R_{s}}{L_{s q}} i_{s q}+\frac{L_{s d}}{L_{s q}} n_{p} \omega i_{s q}+\frac{n_{p} \omega \psi}{L_{s q}}-\frac{1}{L_{s q}} U_{s q}\right. \\
& \left.+\frac{1}{L_{s q}} D_{s q} \operatorname{sgn}\left(S_{2}\right)\right)+I_{2} e_{s q}=-\gamma_{2} S_{2} \\
& K_{3}\left(\dot{i}_{g d s e f}+\frac{R_{c}}{L_{c}} i_{g d}-\omega_{g} i_{g q}-\frac{1}{L_{c}} E_{g d}+\frac{1}{L_{c}} U_{g d}\right. \\
& \left.\quad+\frac{1}{L_{c}} D_{g d} \operatorname{sgn}\left(S_{4}\right)\right)+I_{3} e_{g d}=-\gamma_{3} S_{3} \\
& K_{4}\left(\dot{i}_{g q s e f}+\frac{R_{c}}{L_{c}} i_{g q}+\omega_{g} i_{g d}-\frac{1}{L_{c}} E_{g q}+\frac{1}{L_{c}} U_{g q}\right. \\
& \left.\quad+\frac{1}{L_{c}} D_{g q} \operatorname{sgn}\left(S_{4}\right)\right)+I_{4} e_{g q}=-\gamma_{4} S_{4}
\end{aligned}
$$

Equation (27) can be gotten.

$$
\dot{V} \leq-\sum_{i=1}^{4} \gamma_{i} S_{i}^{2} \leq 0
$$

where $\gamma_{i}>0$. Therefore, the control laws are given by (28) -(31) and the control structure diagram is shown in Figure 2.

$$
\begin{aligned}
U_{s d}= & \frac{L_{s d}}{K_{1}}\left(\gamma_{1} S_{1}+I_{1} e_{s d}\right)+L_{s d} i_{s d s e f}+R_{s} i_{s d} \\
& -L_{s q} n_{p} \omega i_{s q}+D_{s d} \operatorname{sgn}\left(S_{1}\right) \\
U_{s q}= & \frac{L_{s q}}{K_{2}}\left(\gamma_{2} S_{2}+I_{2} e_{s q}\right)+L_{s q} \dot{i}_{s q r e f}+R_{s} i_{s d} \\
& +L_{s d} n_{p} \omega i_{s d}+n_{p} \omega \psi+D_{s q} \operatorname{sgn}\left(S_{2}\right) \\
U_{g d}= & -\frac{L_{c}}{K_{3}}\left(\gamma_{3} S_{3}+I_{3} e_{g d}\right)-L_{c} \dot{i}_{g d s e f}-R_{c} i_{g d} \\
& +L_{c} \omega_{g} i_{g q}+E_{g d}-D_{g d} \operatorname{sgn}\left(S_{3}\right) \\
U_{g q}= & -\frac{L_{c}}{K_{4}}\left(\gamma_{4} S_{4}+I_{4} e_{g q}\right)-L_{c} i_{g q s e f}-R_{c} i_{g q} \\
& -L_{c} \omega_{g} i_{g d}+E_{g q}-D_{g q} \operatorname{sgn}\left(S_{4}\right)
\end{aligned}
$$

From (17) and (27), it is clear that the Lyapunov energy function $V$ is greater than or equal to 0 and the derivative of $V$ is less than or equal to 0 . Hence, the whole system is asymptotically stable based on Lyapunov stability theorem.

3.3. Tracking Accuracy Analysis. In order to analyze the tracking accuracy, we need to introduce Theorem 1 here.

Theorem 1. For any dynamic system with state vector $X=$ $\left[\begin{array}{llll}x_{1} & x_{2} & \ldots & x_{n}\end{array}\right]^{T}$ and assuming $L=f(X) \geq 0$ is a Lyapunov function of system, if $\dot{L} \leq-\sum_{i=1}^{n} k_{i} x_{i}^{2}$ or $\dot{L} \leq-\sum_{i=1}^{n} k_{i}\left|x_{i}\right|$ where $k_{i} \in R^{+}$, then $\lim _{t \rightarrow \infty} x_{i}=0$.

TABLE 1: WECS parameters.

\begin{tabular}{lc}
\hline Parameters & Value \\
\hline Wind turbine inertia moment $J_{\text {tur }}\left[\mathrm{kg} \cdot \mathrm{m}^{2}\right]$ & $2 \times 10^{4}$ \\
Air density $\rho\left[\mathrm{kg} / \mathrm{m}^{3}\right]$ & 1.225 \\
Blade length $R[\mathrm{~m}]$ & 31 \\
Maximum utilization coefficient of wind energy $C_{\mathrm{P}_{\text {_max }}}$ & 0.476 \\
Rated wind speed $v_{\text {rate }}[\mathrm{m} / \mathrm{s}]$ & 14 \\
Rated power $P_{\text {rate }}[\mathrm{MW}]$ & 2 \\
Rated torque $T_{\text {rate }}[\mathrm{kN} \cdot \mathrm{m}]$ & $4 \times 10^{2}$ \\
Rate rotor speed $\omega_{\text {rate }}[\mathrm{rad} / \mathrm{s}]$ & 5 \\
Generator pole logarithm $n_{\mathrm{p}}$ & 102 \\
Permanent flux $\varphi[\mathrm{Wb}]$ & 1.25 \\
Stator-resistance $R_{\mathrm{S}}[\Omega]$ & 0.001 \\
stator-reluctance $L[\mathrm{mH}]$ & 8.35 \\
DC-Link voltage $[\mathrm{V}]$ & 1800 \\
DC-Link capacitor $C[\mathrm{~F}]$ & 0.22 \\
System resistance $R_{c}[\Omega]$ & 0.001 \\
System inductor $L_{c}[\mathrm{mH}]$ & 6 \\
Power grid potential $E_{g d}[\mathrm{~V}]$ & 380 \\
Generator inertia moment $J_{g e n}\left[\mathrm{~kg} \cdot \mathrm{m}^{2}\right]$ & 700 \\
\hline
\end{tabular}

Proof. There are three cases.

(1) If $L \equiv$ constant $\geq 0$, then $0 \equiv \dot{L} \leq-\sum_{i=1}^{n} k_{i} x_{i}^{2} \leq 0$, and further $k_{i} x_{i}^{2}=0$. Due to $k_{i} \neq 0$, thus $x_{i}=0$. This means that there are not continuous and stable equilibrium points $f(X) \equiv$ constant $>0$ such as stable limit cycle in this system. then

(2) Assuming $L(0)=$ constant, due to $\dot{L} \leq-\sum_{i=1}^{n} k_{i} x_{i}^{2}$,

$$
L(0)-L(+\infty) \geq \int_{0}^{+\infty} k_{i} x_{i}^{2} \mathrm{~d} t \geq 0
$$

$\forall x_{i}$, if $\lim _{t \rightarrow \infty} x_{i} \neq 0$, then $\int_{0}^{+\infty} k_{i} x_{i}^{2} \mathrm{~d} t \longrightarrow+\infty$, and furthermore $L(+\infty) \longrightarrow-\infty$. Obviously, this is in contradiction with $L \geq 0$. Thus $\lim _{t \rightarrow \infty} x_{i}=0$.

(3) Given $L(0) \longrightarrow+\infty$, according to Lyapunov stability criterion, the system is stable. So, there must be $t_{1}$ meeting $L\left(t_{1}\right)=$ constant. Otherwise $L(+\infty) \longrightarrow+\infty$. This is clearly in contradiction with system stability. If we redefined $t_{1}$ as 0 , we can get $\lim _{t \rightarrow \infty} x_{i}=0$ by (2).

When $\dot{L} \leq-\sum_{i=1}^{n} k_{i}\left|x_{i}\right|$, we have the same conclusion in the same way.

Based on Theorem 1, we have

$$
\lim _{t \rightarrow+\infty} S=\left[\begin{array}{llll}
0 & 0 & 0 & 0
\end{array}\right]^{\mathrm{T}}
$$

From (12) and (33), we can get

$$
\lim _{t \longrightarrow+\infty} \boldsymbol{e}=\lim _{s \longrightarrow 0} s^{2}(\boldsymbol{K} \boldsymbol{s}+\boldsymbol{I})^{-1} \boldsymbol{S}=\left[\begin{array}{llll}
0 & 0 & 0 & 0
\end{array}\right]^{\mathrm{T}}
$$

The above formula shows that the steady-state error of the system is always 0 regardless of the input. Therefore, the proposed strategy can obtain a good tracking accuracy. 


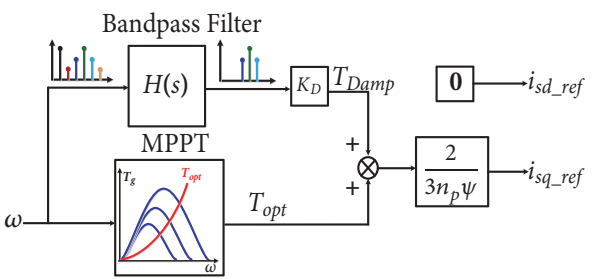

(a)

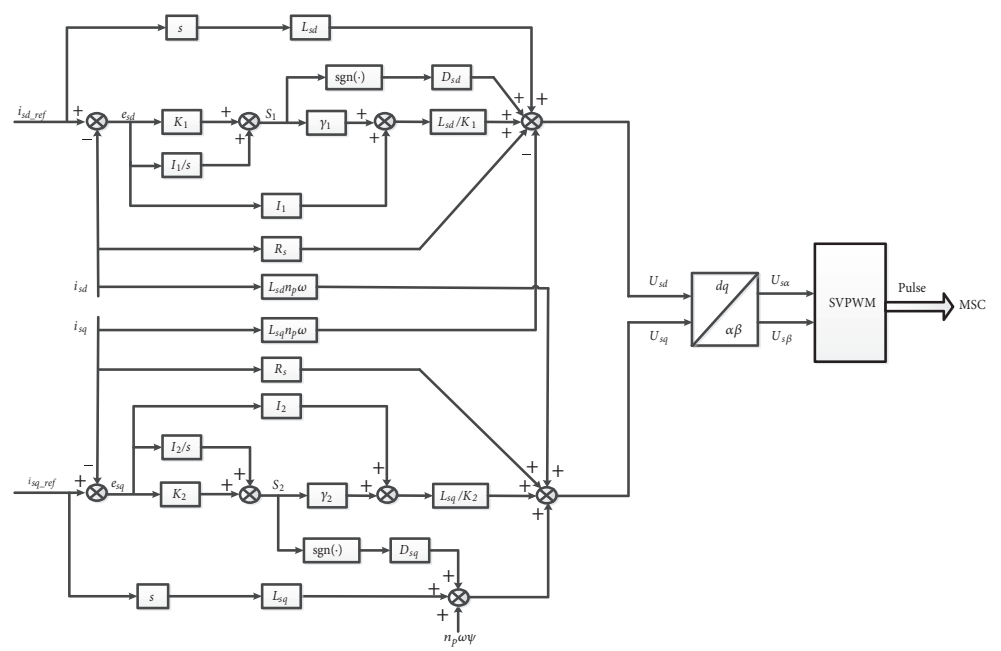

(c)

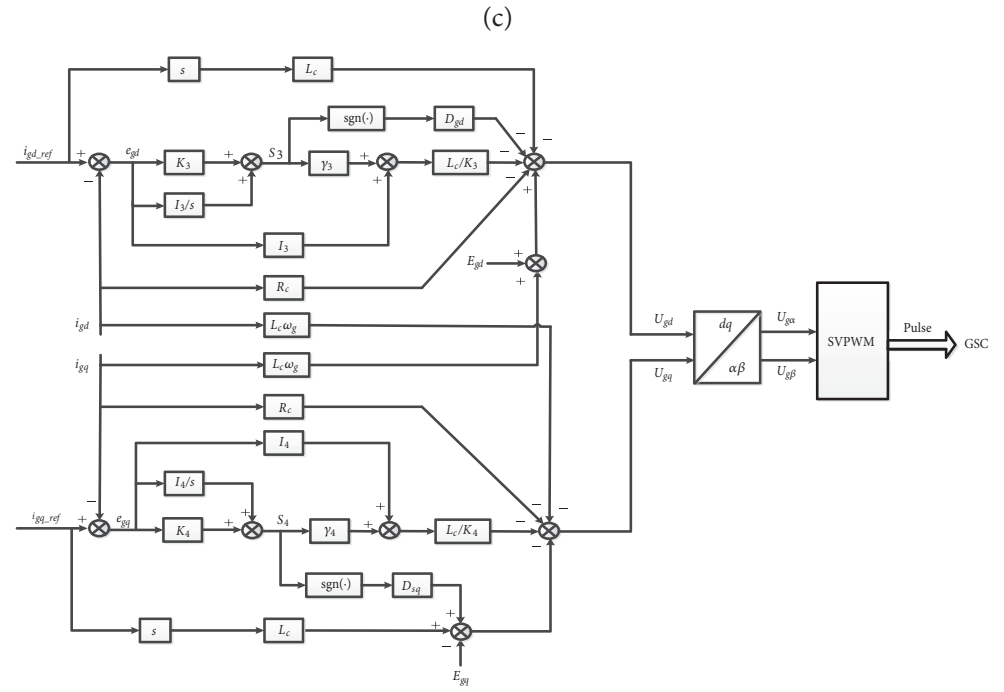

(d) (b)

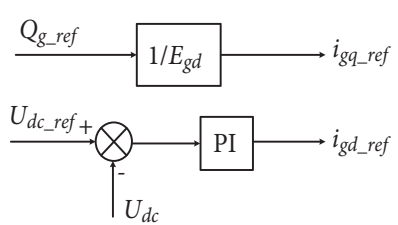

FIGURE 2: Control structure diagram of WECS.

\section{Algorithm Analysis and Verification}

In this section, a detailed simulation test platform is constructed to verify the correctness and effectiveness of the new algorithm, shown in Figure 3. The simulation test platform is based on the MATLAB/Simulink environment and the packaged modules in SimPowerSysterms are used in this simulation test platform, including the wind turbine, PMSG, and VSCs. Meanwhile, the two mass block spring damping model mentioned in [21-31] is adopted to describe the dynamics of flexible drive chain. Therefore, the simulation test platform is relatively close to the actual physical system, due to the adoption of many packaged modules. The controller of WECS consists of MSC controller and GSC controller which are mentioned in Figure 3. The system parameters are shown in Table 1. In general, the actual wind speed is time-varying and random; however we also believe the wind speed is constant for a short period of time. Hence, we assume that the 


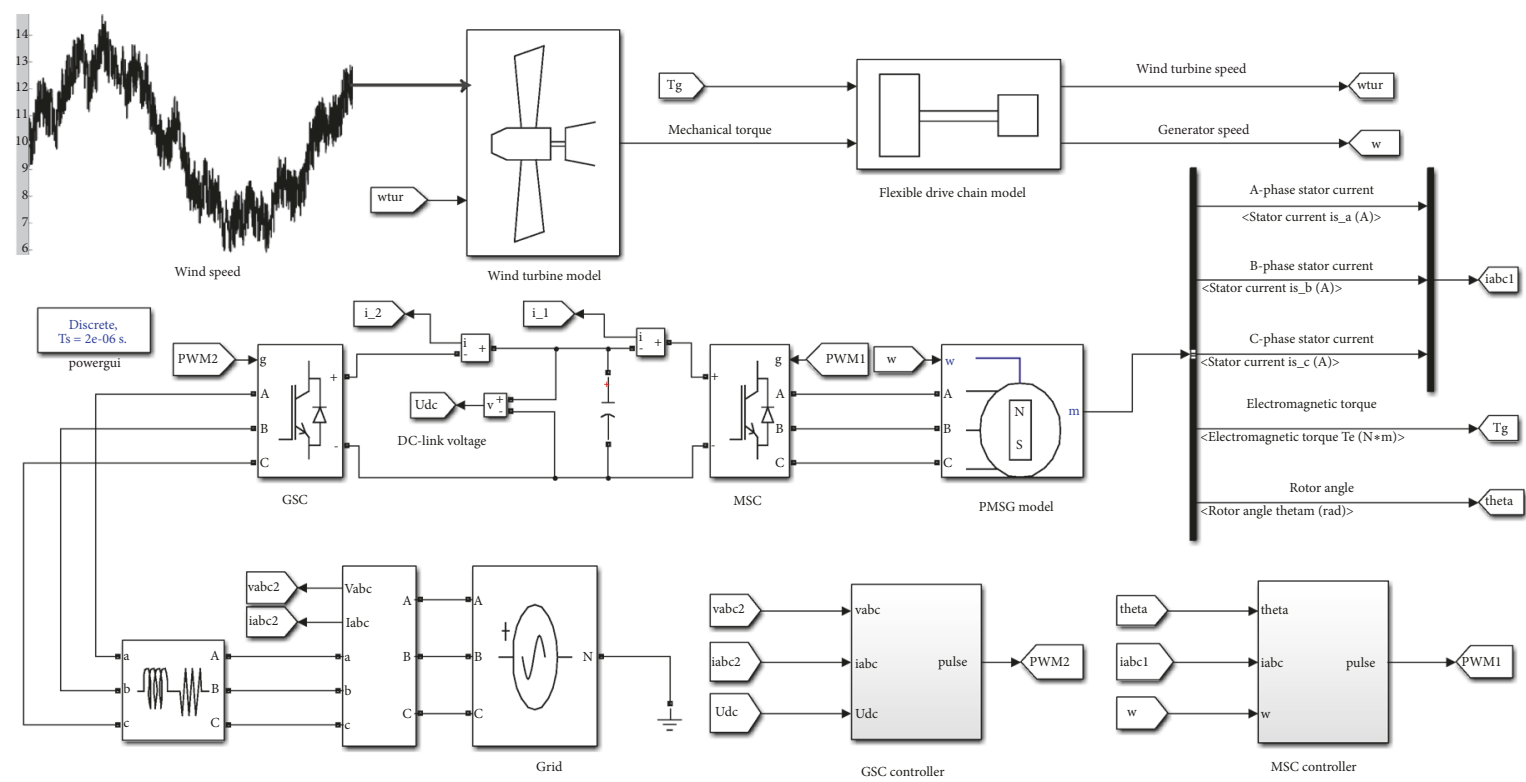

FIGURE 3: Simulation test platform.

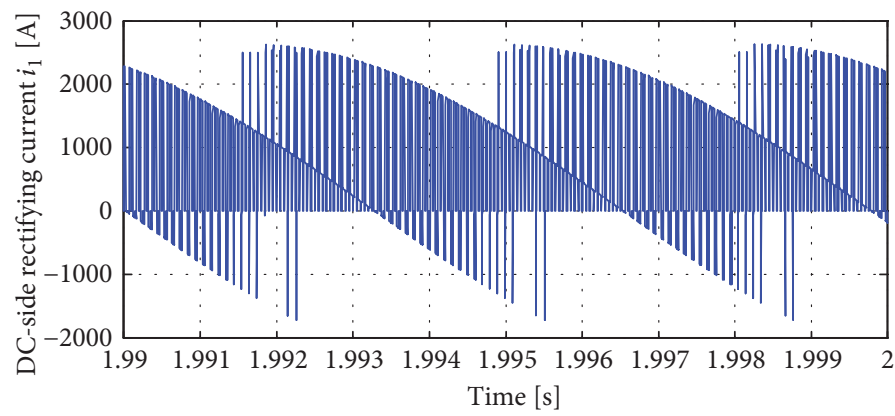

(a)

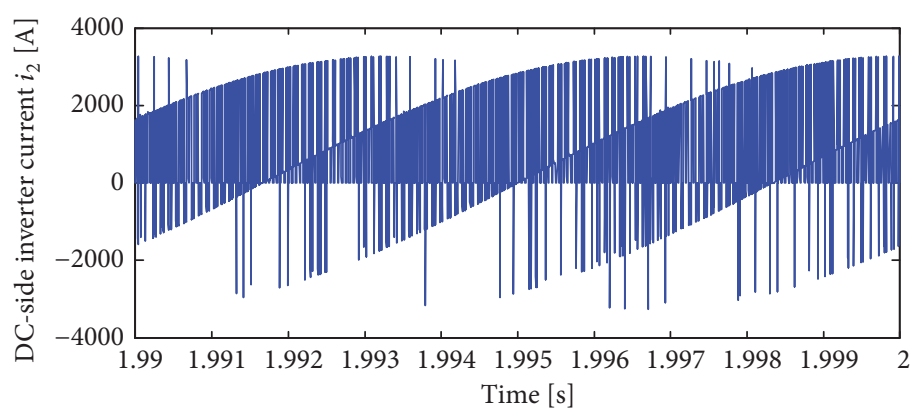

(b)

FIGURE 4: DC-link currents.

wind speed meets $v=12+0.4 \times \operatorname{rand}(t)$. The DC-link currents $i_{1}$ and $i_{2}$ are shown in Figure 4 and the other response curves of WECS are shown in Figure 5.

From Figure 4, we know that the DC-link currents $i_{1}$ and $i_{2}$ are bidirectional. This means that the MSC or GSC is able to switch between rectifier and inverter state. However, because of the mean values of $i_{1}$ and $i_{2}$ are positive, therefore the MSC is basically working as a rectifier and the GSC is mostly in the state of inverter. This is in accordance with the actual accident situation and can verify the accuracy of the model in a sense.

Figure 5 shows the response curves of wind energy utilization coefficient $C_{P}$, DC-link voltage $U_{d c}$, d-axis, and $\mathrm{q}$-axis components of stator current and grid current. The disturbance component of the wind speed is the main causes of $C_{P}, U_{d c}$, current, and power fluctuations. Figure 5(a) depicts the wind energy utilization coefficient $C_{P}$ is always 


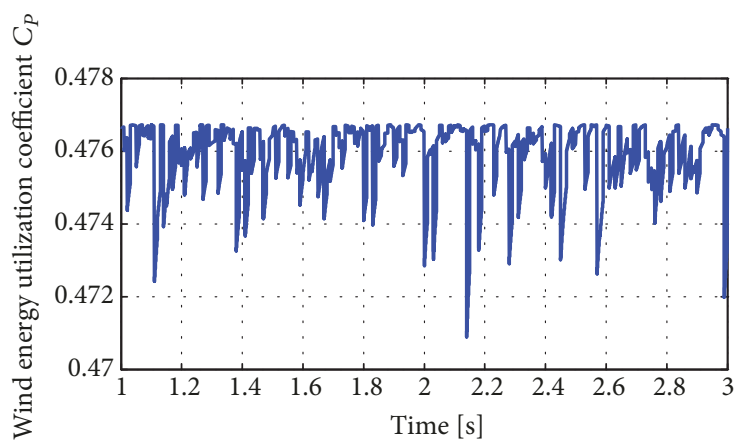

(a)

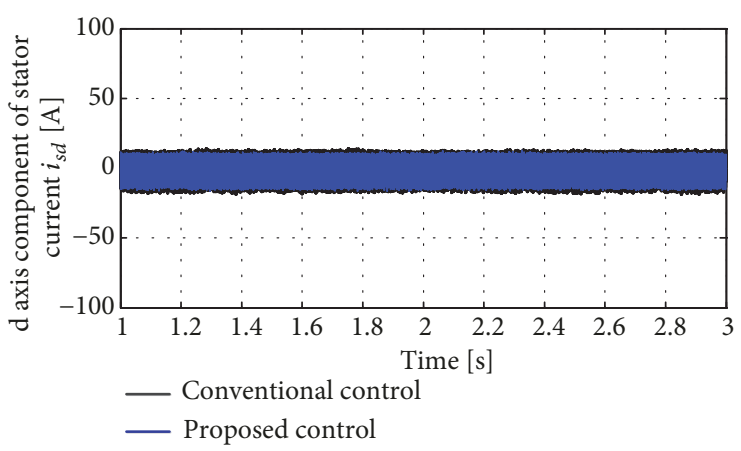

(c)

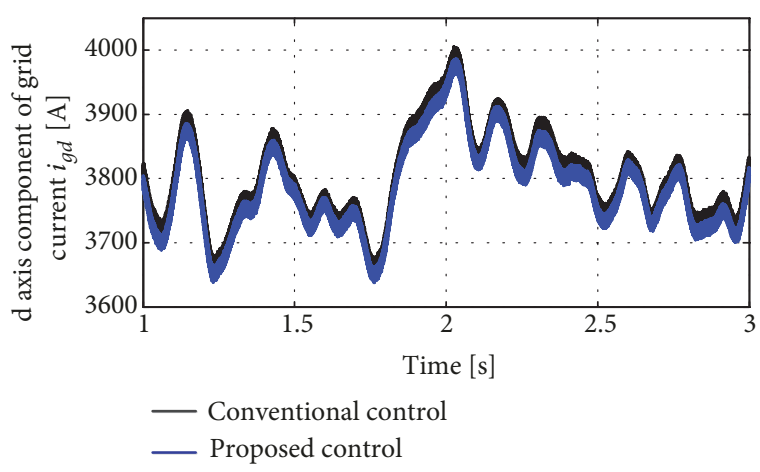

(e)



(b)

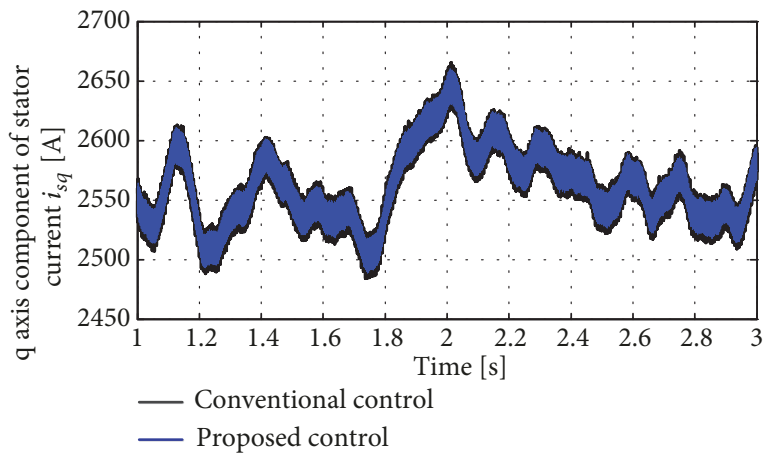

(d)

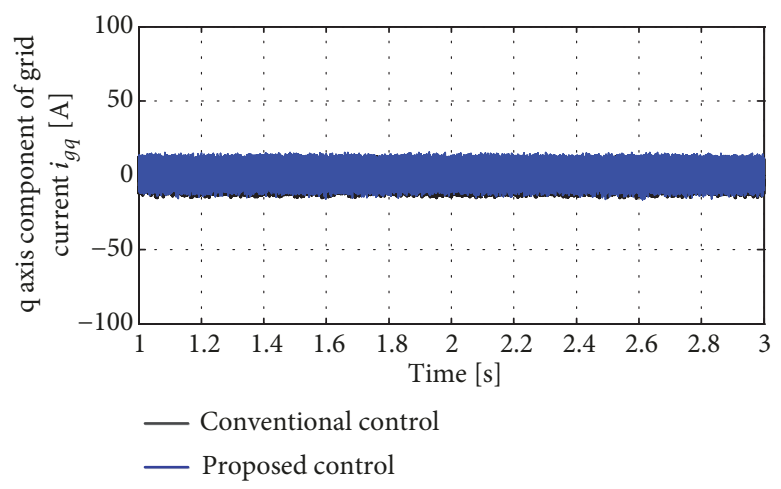

(f)

FIGURE 5: Response curves of WECS.

in the vicinity of the maximum value $C_{P \max }$ (or 0.4763 ) under the proposed control strategy. This implies the WECS is operating in MPPT mode to capture the maximum wind energy under the rated wind speed. It is clear that the DC-link voltage $U_{d c}$ is very close to its reference $U_{d c_{\text {_ref }}}($ or $1800 \mathrm{~V}$ ) and the deviation does not exceed $0.8 \mathrm{~V}$ by Figure $5(\mathrm{~b})$. Figures 5(b)-5(f) show that the proposed control can reduce the current ripple of stator currents and grid currents compared with the conventional control, because the uncertainty of the unmodeled dynamics is taken into account in the design of the proposed controller. In one word, the proposed control strategy has a better robustness than the conventional control strategy.
The electromagnetic torque and sliding mode surfaces curves are shown in Figures 6 and 7 . It is clear that the electromagnetic torque fluctuation under the proposed control method is smaller, compared with the conventional control method. Meanwhile, Figure 7 shows all steady-state values of sliding mode surfaces are tend to zero. Thus, the correctness of the analysis in Section 3.3 is verified by Figure 7. Furthermore, the proposed scheme was further verified for the suppression of current harmonics. Here, we take the A-phase stator current of generator as an example. The A-phase stator current waveform is shown in Figure 8. Obviously, the proposed method also can reduce the current distortion. 


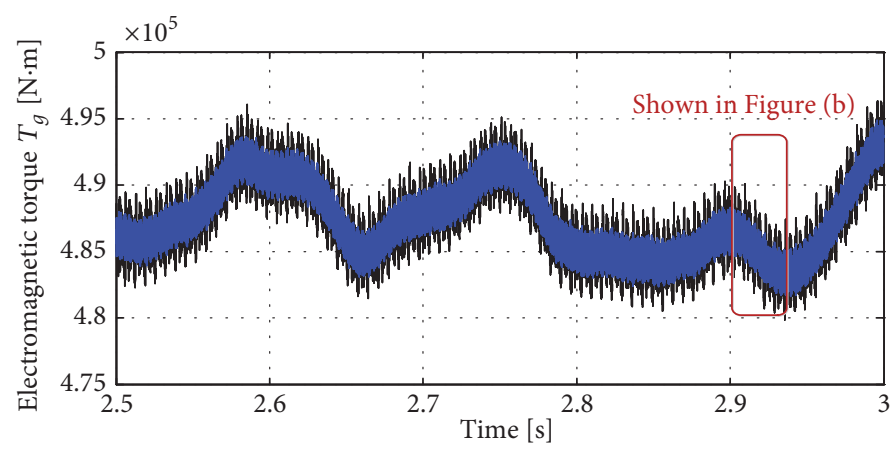

(a)

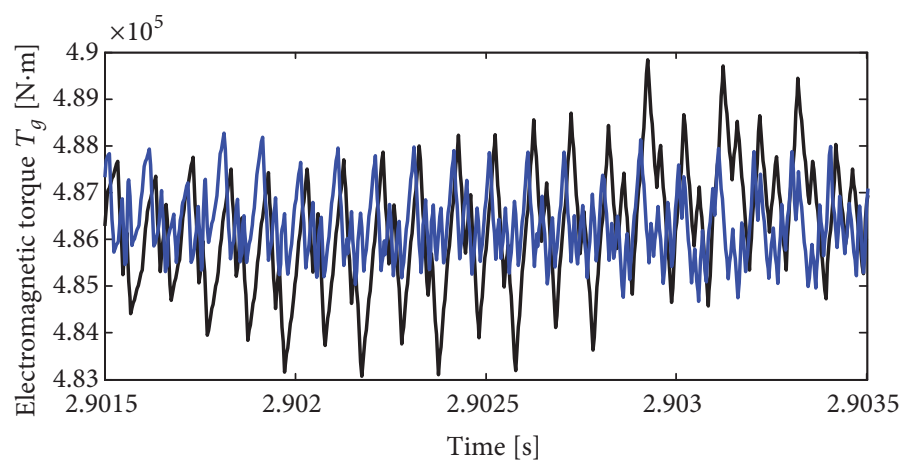

(b)

FIGURE 6: Electromagnetic torque curve.

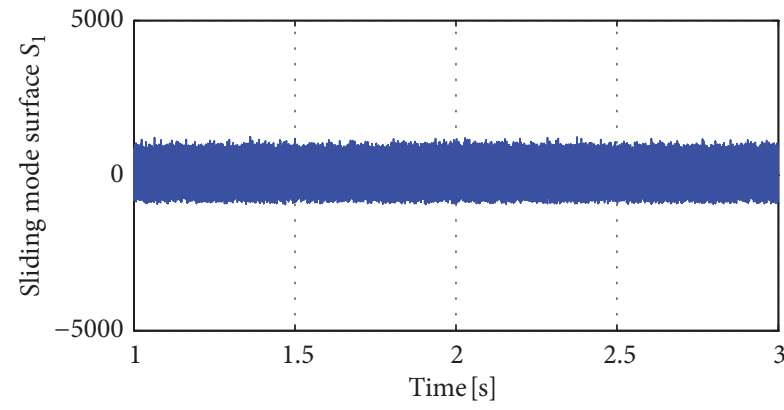

(a)

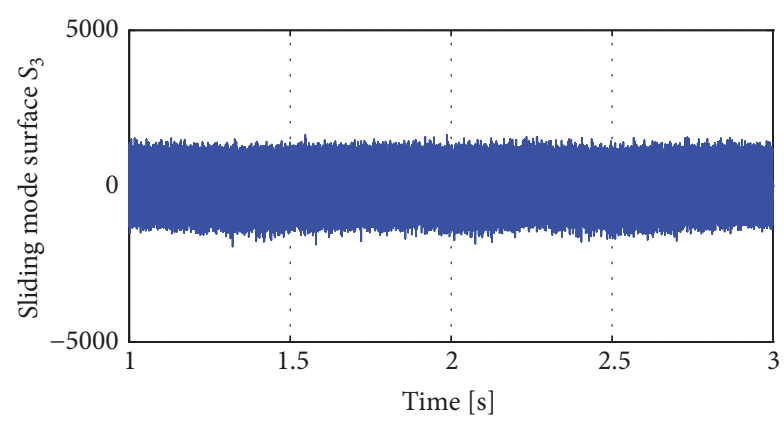

(c)

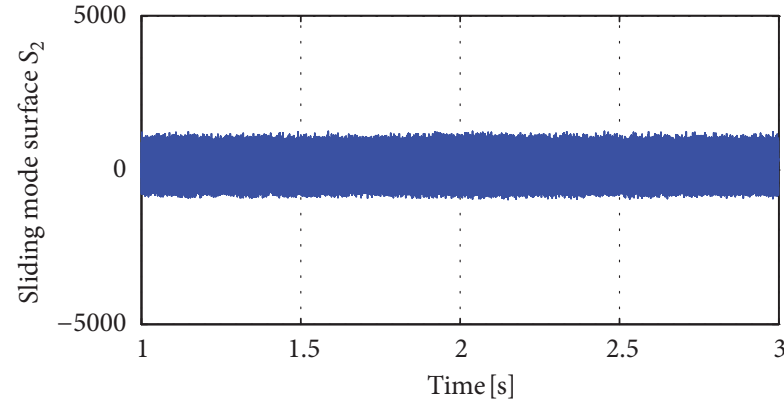

(b)

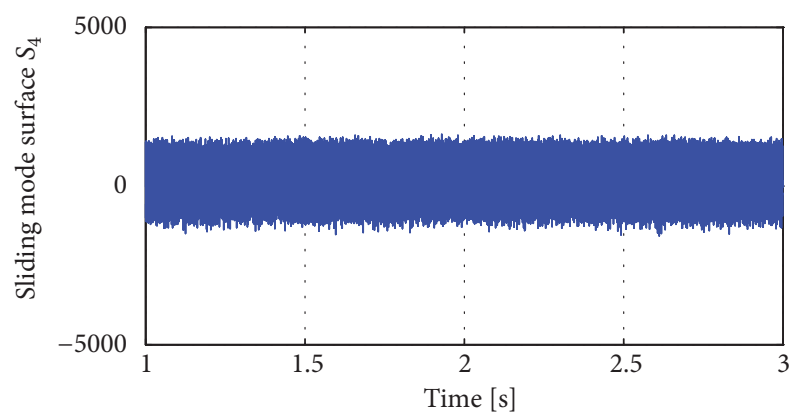

(d)

FIGURE 7: Sliding mode surface curve. 


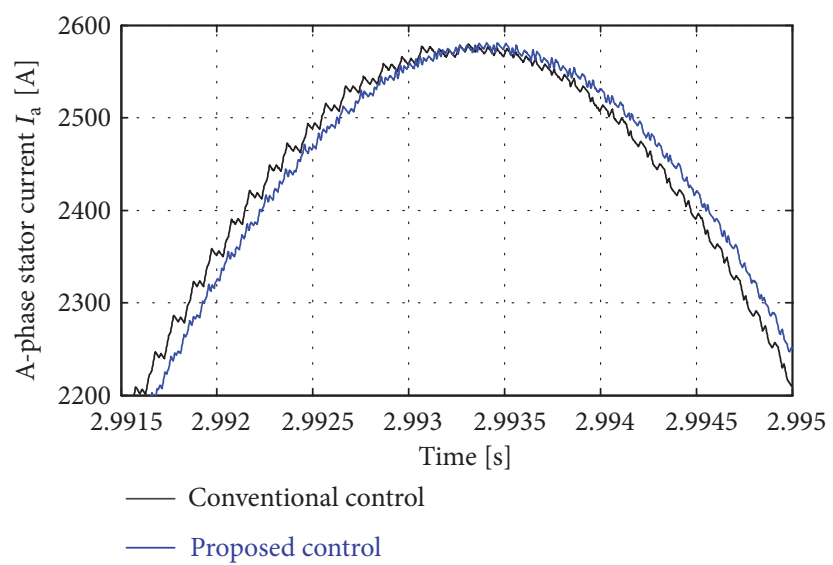

FIgURE 8: A-phase stator current waveform.

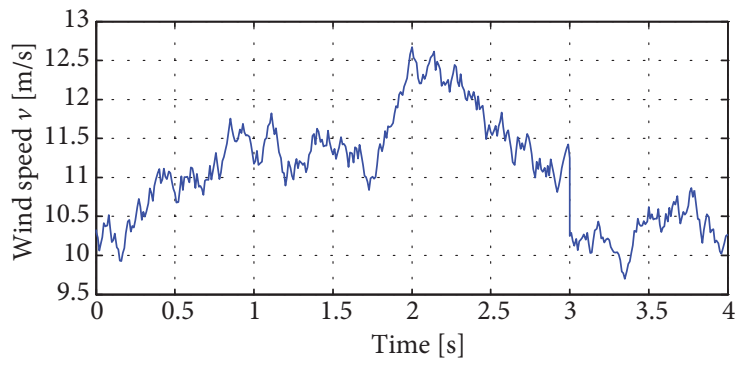

(a)

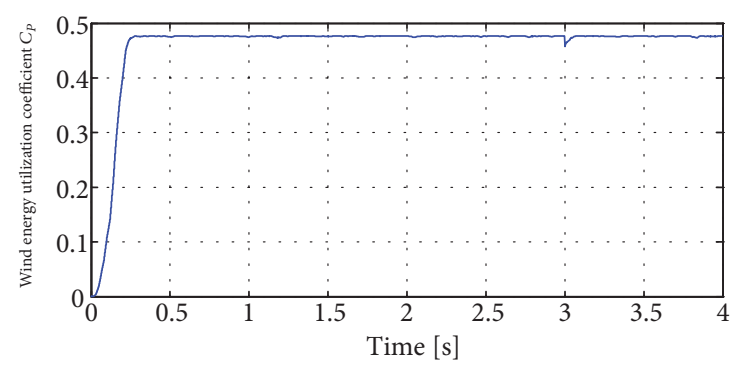

(c)

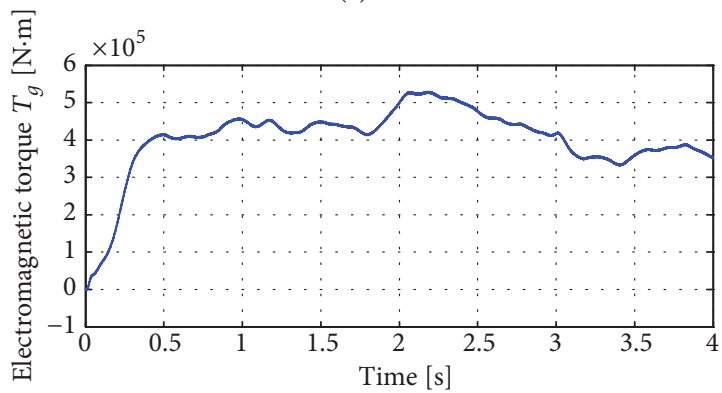

(e)



(g)

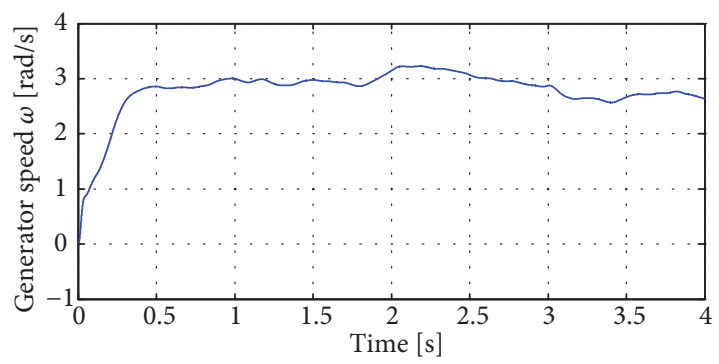

(b)



(d)

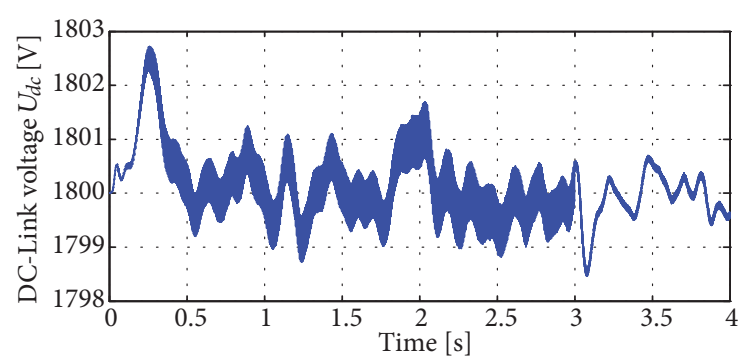

(f)

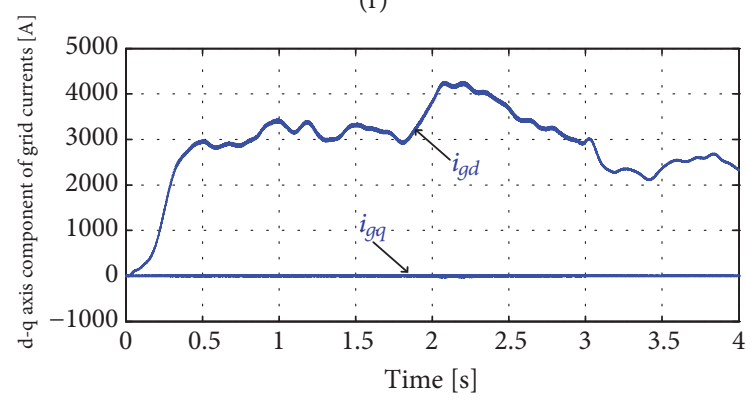

(h)

Figure 9: Variable wind speed and system responses. 
To further verify the effectiveness of the proposed method, the system responses under variable wind speed must be observed and analyzed. As Figure 9(a) shows, the wind speed varied from $10 \mathrm{~m} / \mathrm{s}$ to $12.5 \mathrm{~m} / \mathrm{s}$. At this time, the system response curves under the variable wind speed are shown in Figures 9(b)-9(h). It is clear that the results demonstrated the correctness and effectiveness of the proposed approach again. Figures 9 (c) and 9 (f) show that the wind energy utilization coefficient $C_{P}$ is always maintained at its maximum value $C_{P_{\text {max }}}(0.476)$ and the DC-link voltage $U_{d c}$ always fluctuates around $U_{d c_{-} \text {ref }}(1800 \mathrm{~V})$, whether the wind speed changes. From Figure 9(d), the grid-connected active power is always less than the electromagnetic power due to the copper loss.

\section{Conclusion}

A novel PI-type SMC was proposed to ensure efficient and stability of PMSG-based WECS, in this paper. The presented strategy with a strong robustness for the uncertainties and disturbances of the system can make the closed-loop system globally stable and more performant, compared with the conventional control method. Finally, a 2MW WECS simulation test platform which is based on the MATLAB/MATLAB/SIMULINK/SimPowerSysterms environment was built to verify the maturity and effectiveness of this presented control algorithm. The simulation results indicated that the new method is able to reduce the current distortion and torque fluctuation, which has important actual significance for the control of practical wind turbine.

\section{Data Availability}

The data used to support the findings of this study are available from the corresponding author upon request.

\section{Conflicts of Interest}

The authors declare that there are no conflicts of interest regarding the publication of this paper.

\section{Acknowledgments}

The research was supported by Key R\&D projects in Shaanxi (Grant no. 2017GY-061).

\section{References}

[1] J. Liu, H. Meng, Y. Hu, Z. Lin, and W. Wang, "A novel MPPT method for enhancing energy conversion efficiency taking power smoothing into account," Energy Conversion and Management, vol. 101, pp. 738-748, 2015.

[2] D. Song, J. Yang, X. Fan et al., "Maximum power extraction for wind turbines through a novel yaw control solution using predicted wind directions," Energy Conversion and Management, vol. 157, pp. 587-599, 2018.

[3] F. Zhou and J. Liu, "Pitch controller design of wind turbine based on nonlinear PI/PD control," Shock and Vibration, vol. 2018, Article ID 7859510, 14 pages, 2018.
[4] D. Song, X. Fan, J. Yang, A. Liu, S. Chen, and Y. H. Joo, "Power extraction efficiency optimization of horizontal-axis wind turbines through optimizing control parameters of yaw control systems using an intelligent method," Applied Energy, vol. 224, pp. 267-279, 2018.

[5] F. Zhou and J. Liu, "A robust control strategy research on PMSGbased WECS considering the uncertainties," IEEE Access, vol. 6, pp. 51951-51963, 2018.

[6] S. Li, T. A. Haskew, R. P. Swatloski, and W. Gathings, "Optimal and direct-current vector control of direct-driven PMSG wind turbines," IEEE Transactions on Power Electronics, vol. 27, no. 5, pp. 2335-2337, 2012.

[7] P. Li, R.-X. Li, Y. Cao, D.-Y. Li, and G. Xie, "Multi-objective sizing optimization for island microgrids using triangular aggregation model and levy-harmony algorithm," IEEE Transactions on Industrial Informatics, p. 99, 2017.

[8] P. Li, R. Dargaville, Y. Cao, D. Li, and J. Xia, "Storage aided system property enhancing and hybrid robust smoothing for large-scale pv systems," IEEE Transactions on Smart Grid, vol. 8, no. 6, pp. 2871-2879, 2017.

[9] M. Little and K. Pope, "Performance modelling for wind turbines operating in harsh conditions," International Journal of Energy Research, vol. 41, no. 3, pp. 417-428, 2017.

[10] J. Yan, H. Lin, Y. Feng, X. Guo, Y. Huang, and Z. Q. Zhu, "Improved sliding mode model reference adaptive system speed observer for fuzzy control of direct-drive permanent magnet synchronous generator wind power generation system," IET Renewable Power Generation, vol. 7, no. 1, pp. 28-35, 2013.

[11] Y. A.-R. I. Mohamed, "Design and implementation of a robust current-control scheme for a PMSM vector drive with a simple adaptive disturbance observer," IEEE Transactions on Industrial Electronics, vol. 54, no. 4, pp. 1981-1988, 2007.

[12] R. Errouissi, M. Ouhrouche, W.-H. Chen, and A. M. Trzynadlowski, "Robust nonlinear predictive controller for permanentmagnet synchronous motors with an optimized cost function," IEEE Transactions on Industrial Electronics, vol. 59, no. 7, pp. 2849-2858, 2012.

[13] H. Liu and S. Li, "Speed control for PMSM servo system using predictive functional control and extended state observer," IEEE Transactions on Industrial Electronics, vol. 59, no. 2, pp. 11711183, 2012.

[14] R. Errouissi, A. Al-Durra, and M. Debouza, "A novel design of PI current controller for PMSG-based wind turbine considering transient performance specifications and control saturation," IEEE Transactions on Industrial Electronics, vol. 65, no. 11, pp. 8624-8634, 2018.

[15] X. H. Yu and O. Kaynak, "Sliding-mode control with soft computing: a survey," IEEE Transactions on Industrial Electronics, vol. 56, no. 9, pp. 3275-3285, 2009.

[16] O. Kaynak, K. Erbatur, and M. Ertugrul, "The fusion of computationally intelligent methodologies and sliding-mode control-a survey," IEEE Transactions on Industrial Electronics, vol. 48, no. 1, pp. 4-17, 2001.

[17] L. Shang and J. Hu, "Sliding-mode-based direct power control of grid-connected wind-turbine-driven doubly fed induction generators under unbalanced grid voltage conditions," IEEE Transactions on Energy Conversion, vol. 27, no. 2, pp. 362-373, 2012.

[18] S. M. Mozayan, M. Saad, H. Vahedi, H. Fortin-Blanchette, and M. Soltani, "Sliding mode control of PMSG wind turbine based on enhanced exponential reaching law," IEEE Transactions on Industrial Electronics, vol. 63, no. 10, pp. 6148-6159, 2016. 
[19] C. Evangelista, P. Puleston, F. Valenciaga, and L. M. Fridman, "Lyapunov-designed super-twisting sliding mode control for wind energy conversion optimization," IEEE Transactions on Industrial Electronics, vol. 60, no. 2, pp. 538-545, 2013.

[20] J. Yang, S. Li, and X. Yu, "Sliding-mode control for systems with mismatched uncertainties via a disturbance observer," IEEE Transactions on Industrial Electronics, vol. 60, no. 1, pp. 160-169, 2013.

[21] R. Errouissi and A. Al-Durra, "A novel PI-type sliding surface for PMSG-based wind turbine with improved transient performance," IEEE Transactions on Energy Conversion, vol. 33, no. 2, pp. 834-844, 2018.

[22] C. Xia, G. Jiang, W. Chen, and T. Shi, "Switching-gain adaptation current control for brushless DC motors," IEEE Transactions on Industrial Electronics, vol. 63, no. 4, pp. 2044-2052, 2016.

[23] J. Hu, H. Nian, B. Hu, Y. He, and Z. Q. Zhu, "Direct active and reactive power regulation of DFIG using sliding-mode control approach," IEEE Transactions on Energy Conversion, vol. 25, no. 4, pp. 1028-1039, 2010.

[24] B. Beltran, T. Ahmed-Ali, and M. El Hachemi Benbouzid, "Sliding mode power control of variable-speed wind energy conversion systems," IEEE Transactions on Energy Conversion, vol. 23, no. 2, pp. 551-558, 2008.

[25] C. J. Smith, C. J. Crabtree, and P. C. Matthews, "Impact of wind conditions on thermal loading of PMSG wind turbine power converters," in Proceedings of the 8th IET International Conference on Power Electronics, Machines and Drives, PEMD 2016, UK, April 2016.

[26] J. Lu, Y. Hu, X. Zhang, Z. Wang, J. Liu, and C. Gan, "High frequency voltage injection sensorless control technique for ipmsms fed by a three-phase four-switch inverter with a single current sensor," IEEE/ASME Transactions on Mechatronics, vol. 99, no. 1, p. 1, 2018.

[27] J. Lu, X. Zhang, Y. Hu, J. Liu, C. Gan, and Z. Wang, "Independent phase current reconstruction strategy for ipmsm sensorless control without using null switching states," IEEE Transactions on Industrial Electronics, vol. 99, p. 1, 2017.

[28] F. Fateh, W. N. White, and D. Gruenbacher, "Torsional vibrations mitigation in the drivetrain of DFIG-based gridconnected wind turbine," IEEE Transactions on Industry Applications, vol. 53, no. 6, pp. 5760-5767, 2017.

[29] I. P. Girsang, J. S. Dhupia, E. Muljadi, M. Singh, and J. Jonkman, "Modeling and control to mitigate resonant load in variablespeed wind turbine drivetrain," IEEE Journal of Emerging and Selected Topics in Power Electronics, vol. 1, no. 4, pp. 277-286, 2013.

[30] E. A. Bossanyi, "The design of closed loop controllers for wind turbines," Wind Energy, vol. 3, no. 3, pp. 149-163, 2000.

[31] E. A. Bossanyi, "Wind turbine control for load reduction," Wind Energy, vol. 6, no. 3, pp. 229-244, 2003.

[32] Bossanyi, Ervin, and D. Witcher, "Controller for 5MW reference turbine," Project UpWind, Bristol, England, 2009.

[33] F. Zhang, W. E. Leithead, and O. Anaya-Lara, "A combined controller design of power system stabilizer and wind turbine drivetrain damping filter," in Proceedings of the International Conference on Sustainable Power Generation and Supply, SUPERGEN 2012, p. 41, September 2012.

[34] J. Licari, C. E. Ugalde-Loo, J. B. Ekanayake, and N. Jenkins, "Damping of torsional vibrations in a variable-speed wind turbine," IEEE Transactions on Energy Conversion, vol. 28, no. 1, pp. 172-180, 2013.
[35] D. H. Anca and G. Michalke, "Modelling and control of variablespeed multi-pole permanent magnet synchronous generator wind turbine," Wind Energy, vol. 11, pp. 537-554, 2008.

[36] T. Orlowska-Kowalska and K. Szabat, "Damping of torsional vibrations in two-mass system using adaptive sliding neurofuzzy approach," IEEE Transactions on Industrial Informatics, vol. 4, no. 1, pp. 47-57, 2008.

[37] R. Muszynski and J. Deskur, "Damping of torsional vibrations in high-dynamic industrial drives," IEEE Transactions on Industrial Electronics, vol. 57, no. 2, pp. 544-552, 2010.

[38] A. Lorenzo-Bonache, A. Honrubia-Escribano, F. JiménezBuendía, Á. Molina-García, and E. Gómez-Lázaro, "Generic type 3 wind turbine model based on IEC 61400-27-1: Parameter analysis and transient response under voltage dips," Energies, vol. 10, no. 9, 2017. 


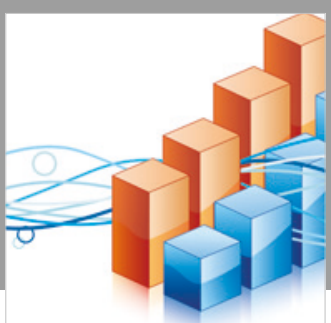

Advances in

Operations Research

\section{-n-m}
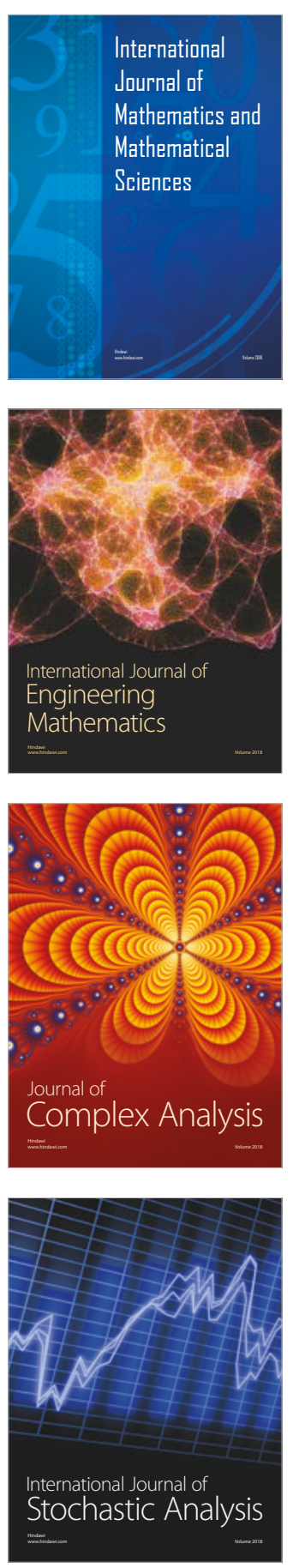
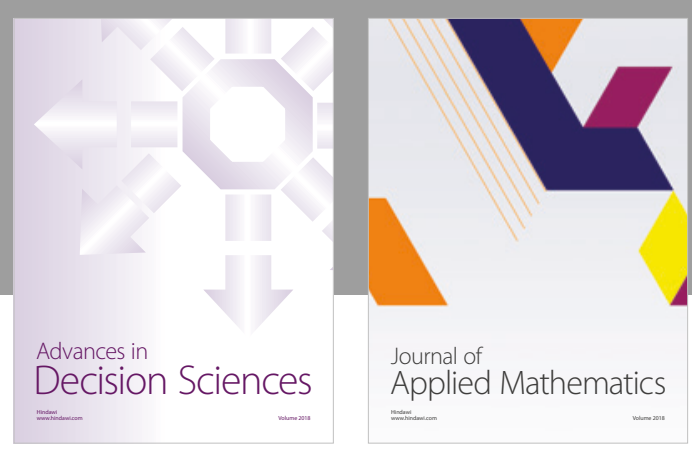

Journal of

Applied Mathematics
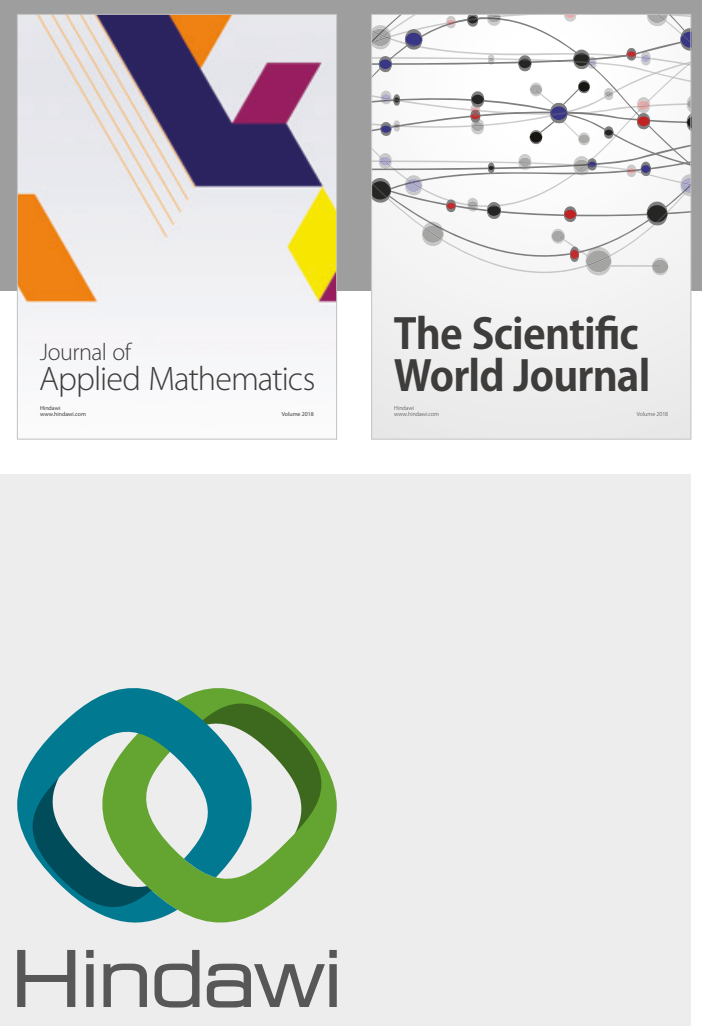

Submit your manuscripts at

www.hindawi.com

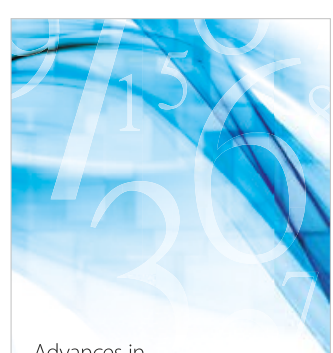

Advances in
Numerical Analysis


Mathematical Problems in Engineering

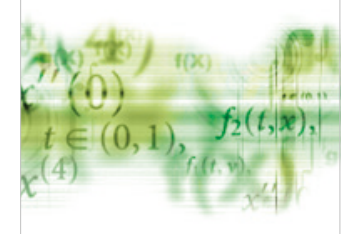

International Journal of

Differential Equations

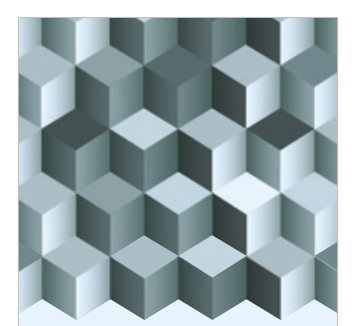

Journal of

Function Spaces
The Scientific

World Journal

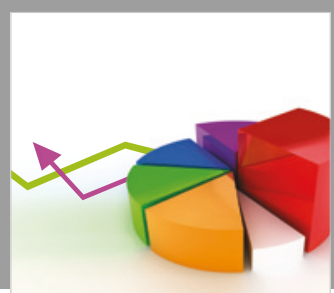

Journal of

Probability and Statistics
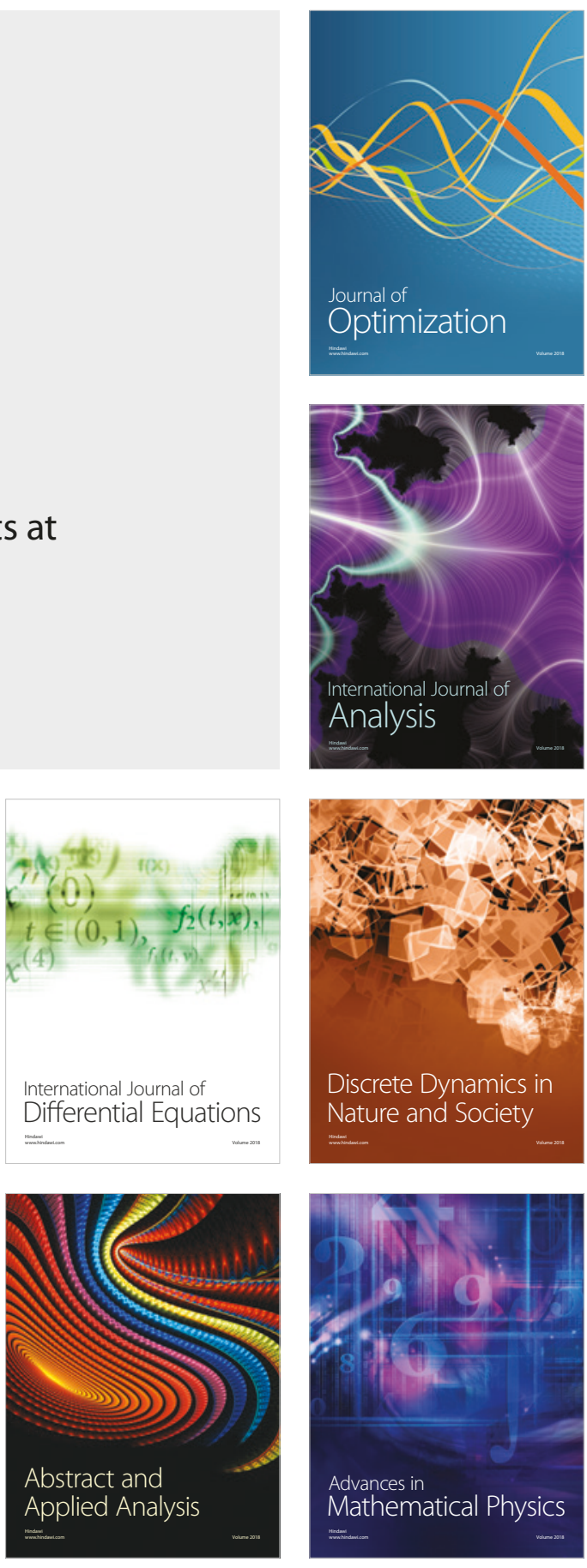